\title{
HOW TO ALLOCATE SCARCE HEALTH RESOURCES WITHOUT DISCRIMINATING AGAINST PEOPLE WITH DISABILITIES
}

\author{
Tyler M. JOHN, ${ }^{*}$ JOSEPh Millum ${ }^{\dagger}$, David WASSERMaN $\ddagger$
}

\begin{abstract}
One widely used method for allocating health care resources involves the use of cost-effectiveness analysis (CEA) to rank treatments in terms of quality-adjusted life-years (QALYs) gained. CEA has been criticized for discriminating against people with disabilities by valuing their lives less than those of non-disabled people. Avoiding discrimination seems to lead to the 'QALY trap': we cannot value saving lives equally and still value raising quality of life. This paper reviews existing responses to the QALY trap and argues that all are problematic. Instead, we argue that adopting a moderate form of prioritarianism avoids the QALY trap and disability discrimination.
\end{abstract}

Keywords: QALY, disability, priority setting, health care, prioritarianism

\section{INTRODUCTION}

In contemporary societies, limited health care budgets mean that not all health care interventions that would be beneficial can be provided to the people who need them. Policymakers within health care systems must therefore set priorities for which interventions to fund. One widely used tool for allocating health care resources involves the use of

* Clinical Center Department of Bioethics, Building 10 Room 1C118, Bethesda, MD 20892, USA. Email: tyler.john@rutgers.edu.

$\dagger$ Clinical Center Department of Bioethics and Fogarty International Center, Building 10 Room 1C118, Bethesda, MD 20892, USA. Email: joseph.millum@nih.gov. URL: http:// www.bioethics.nih.gov/people/millum-bio.shtml

$\ddagger$ Clinical Center Department of Bioethics, Building 10 Room 1C118, Bethesda, MD 20892, USA. Email: david.wasserman@nih.gov. URL: http://www.bioethics.nih.gov/ people/wasserman-bio.shtml 
Cost-Effectiveness Analysis (CEA) to rank treatments. If we can assess the benefits and costs of each intervention, we can use CEA to compare them, and select the intervention with the most favourable cost-benefit ratio. For example, the National Institute for Health and Care Excellence (NICE) conducts technology appraisals of new treatments being considered for the National Health Service in England and Wales. Its binding recommendations are largely based on a cost-effectiveness threshold (NICE 2005).

The use of CEA to set health care spending priorities has been widely criticized. One of the most discussed criticisms is that it unfairly discriminates against people with disabilities and chronic health conditions. CEA assesses the benefits of health care interventions on the basis of the quality as well as quantity of life-years they save. This methodology seems to imply that extending the lives of people with disabilities and chronic health conditions is less valuable than extending the lives of those without them. ${ }^{1}$

In this essay, we review the alternatives to CEA that have been developed in response to this criticism. We argue that the alternative allocation schemes philosophers and health economists have proposed all have problematic implications. Instead, we argue that adopting a moderate form of prioritarianism is the best way to deal with the disability discrimination concern. It provides a theoretically grounded alternative to CEA that gives intuitively plausible verdicts for many cases and does not invidiously discriminate against people with conditions that lower their quality of life.

\section{THE QALY TRAP}

Health interventions may target both morbidity and mortality. In order to rationally set priorities for health spending we therefore must be able to compare the value of averting different states of illness and death. Summary measures of health, such as quality-adjusted life years (QALYs), provide a common measure of the value of different health states. One straightforward way to calculate the value of a health state in terms of QALYs is to take the health-related quality of life score of a health state and multiply it by the duration of the health state. ${ }^{2}$ One QALY is equivalent to a year lived in perfect health, that is, in a health state with a healthrelated quality of life score of 1.0. One year spent in sub-optimal health will have a value less than one QALY. For example, if paraplegia had

1 See, among others, Harris (1987, 1995), Ubel et al. (2000), Brock (2009), Kamm (2009), Nord et al. (2009) and Bognar (2010).

${ }^{2}$ In this paper we ignore other complications in the construction of QALYs, such as the use of time-discounting, since they would complicate matters without making a difference to our normative analysis. 
a quality score of 0.55 , then one year of paraplegia would be valued at 0.55 QALYs. ${ }^{3}$ Curing paraplegia would be worth 0.45 QALYs per year. A year of a health state that is as bad as being dead is valued at 0 QALYs. ${ }^{4}$

QALYs can be used in cost-effectiveness analysis (CEA) to compare the relative value of different interventions. Suppose that Yin and Sam were each in a traffic accident. Yin suffered severe lumbar spinal torsion, and without treatment will be paraplegic for the rest of her life. With the proper surgery she can make a full recovery. Sam suffered damages to the ligament in his ankle, and without treatment will suffer from ankle instability for the rest of his life. With the proper surgery, he can make a full recovery. Suppose that the quality of life score of paraplegia is 0.55 and the quality of life score of ankle instability is 0.80 . Yin and Sam are each expected to live 40 years after the accident and the two surgeries cost the same amount. Treating Yin will yield 18 QALYs, because her 40 years of life will have a quality 0.45 units better than it otherwise would have had. Treating Sam will yield 8 QALYs, because his 40 years of life will have a quality 0.20 units better than it otherwise would have had. ${ }^{5}$ Because the two interventions cost the same, if we allocate resources strictly on the basis of CEA we should prioritize treating Yin over treating Sam when we cannot treat both.

Many people find the results of QALY aggregation less plausible when deciding how to allocate interventions that save people's lives. Suppose Valentina and Deepak both need a liver transplant and will die without it. Other than her liver failure, Valentina is completely healthy. If she receives the organ, her health-related quality of life will be 1.0 for 20 years, until she dies. Deepak, however, not only has a failed organ, but is paraplegic. If he receives the organ, his health-related quality of life will be 0.55 for 20 years, until he dies. Many people think that Valentina and Deepak should be given equal priority, even those who agree that someone with paraplegia normally has substantially lower quality of life than someone who is able-bodied. Deciding the transplant on the basis of QALYs tells us differently. If Valentina is treated, she will gain 20 QALYs, but if Deepak is treated he will only gain 11 QALYs. ${ }^{6}$ Thus, CEA tells us

${ }^{3}$ We are not here endorsing these values, which come from time trade-off research from Lin et al. (2006). For a critical discussion of quality score assignments in cost-effectiveness analysis, see sections 3.2 .1 and 5.1 of this paper.

${ }^{4}$ There might be health states that are regarded as being worse than death. Although standard ways of constructing QALYs assume health state valuations between 0 and 1 there is no reason, in principle, why values below 0 could not be accommodated.

${ }^{5} 40$ years $\times 0.45$ quality $=18$ QALYs; 40 years $\times 0.2$ quality $=8$ QALYs.

${ }^{6} 20$ years $\times 1.0$ quality $=20$ QALYs; 20 years $\times 0.55$ quality $=11$ QALYs. 
to prioritize treating Valentina over treating Deepak. To many, this seems to discriminate against Deepak on the basis of his disability.

We might try to incorporate this belief about the equal importance of saving people's lives into CEA. We could assign the same value to any year of extra life, whether that year is spent at full or sub-optimal health. However, if a year in any health state has the same value, then this implies that there is no value to curing chronic health conditions. Recall that, on the original quality of life valuation of paraplegia (0.55), curing it would provide 0.45 QALYs per year of life. This was because curing paraplegia raised a patient's health utility score by 0.45 . But to account for the belief about the value of life-saving, we must say that a year of a patient's life with paraplegia has the same value as a year of her life without paraplegia (1.0 QALY). Thus, a treatment that cured a patient's paraplegia would provide no additional value. Because summary measures of health like QALYs combine both quality and quantity of life in a single unit, they cannot simultaneously accommodate our intuitions about raising quality of life and saving lives. If we want to value interventions that raise people's quality of life, we are forced to give less value to saving the lives of those with lower quality of life. On the other hand, if we want to give equal value to saving the lives of those with lower quality of life, we are forced to give no value to raising people's quality of life. As Ubel et al. conclude: 'the QALY model has us trapped' (2000: 895).

The 'QALY trap' illuminates a broader challenge with reconciling common views about the importance of curing chronic conditions and valuing the lives of people with disabilities. As we just noted, many people endorse the principle of Equal Value to Saving Lives, according to which it is equally valuable to save the life of someone with low quality of life as someone with high quality. ${ }^{8}$ Most also endorse Value to Reducing Morbidity: all else equal, it is better to save someone's life and cure her disability than save her life but leave her disabled. By transitivity of the betterness relation, it follows from these two principles that we should endorse Unequal Value for Equal Outcomes: it is better to save the life of someone with a chronic health condition who will then be healthy, than to save the life of someone already healthy who will then be healthy. This seems counter-intuitive. After all, the outcomes of the treatments are identical: in either case, we save the life of someone who goes on to live in full health. If the outcomes are the same, they should be assigned the same value. We know of no philosophers who defend Unequal Value for Equal Outcomes. No matter how we proceed, it appears that we must

7 A survey from Ubel et al. (1999) provides evidence that many people find this discriminatory.

8 Throughout, we assume that the quality of life of the people we discuss is such as to make continued life worth living. 
accept some prima facie counter-intuitive view. We must reject Equal Value to Saving Lives, Value to Reducing Morbidity, or the transitivity of betterness, or we must accept Unequal Value for Equal Outcomes.

We can generalize the problem further by not limiting ourselves to scarce health care resources, to disabilities as the source of reduced quality of life, or to health-related quality of life. In a world of scarce resources, policymakers must make choices about saving the lives of people with great disparities in expected quality of life, whatever their source. And they must make tradeoffs between saving lives and improving quality of life, whether through health care or the provision of other resources. We return to this point in section 4; for the moment we follow the existing literature by focusing on disabilities as a source of reduced health-related quality of life.

\section{RESPONSES TO THE QALY TRAP}

\subsection{Reject Equal Value to Saving Lives}

One response is to deny that saving the lives of people who will have lives with lower levels of well-being is as valuable as saving the lives of people who will have higher levels of well-being. Among others, this response has been adopted by Peter Singer, and by Nick Beckstead and Toby Ord.

Singer and a group of philosophers at Monash University (Singer et al. 1995) make a 'contractarian' case for rejecting Equal Value to Saving Lives. Following John Rawls, they hold that a just social arrangement is one to which rational egoists would consent from behind a 'veil of ignorance', i.e. not knowing which position in society they would occupy. They envision 'people choosing a basis for allocating health care without knowing whether, at some point in their lives, they will be in need of health care to prolong their lives' or whether, if this happens, they will be among those with high levels of well-being in their lives or those with low levels of well-being in their lives (Singer et al. 1995: 148). ${ }^{9}$ Singer et al. argue that these rational egoists would reject Equal Value to Saving Lives, and therefore that so-called 'disability discrimination' in CEA is not unjust.

Suppose that you are a rational egoist deliberating about whether society should save the life of someone with a quality of life of 0.55 or someone with a quality of life of 1.0, both of whom will live for the same length of time if their lives are saved. From behind the veil of ignorance, you do not know which you will be: you have a $50 \%$ chance of being the person at 0.55 and a $50 \%$ chance of being the person at 1.0 . This means

9 Singer describes those with low levels of well-being in their lives as having a lower 'interest in continuing to live'. It might be argued that having a lower level of well-being does not imply having a lower interest in continuing life. We sidestep this issue by speaking only of 'lower levels of well-being'. 
that if the person at 0.55 is saved, there is a $50 \%$ chance that you will end up living a life at 0.55 after $t$, and a $50 \%$ chance that you will die at $t$. But if the person at 1.0 is saved, there is a $50 \%$ chance that you will end up living a life at 1.0 after $t$, and a $50 \%$ chance that you will die at $t$. Since it is better for you if you have a quality of life of 1.0 than a quality of life of 0.55 , saving the person at 1.0 is the rational choice. According to Singer et al., then, if the veil of ignorance is the correct way to determine whether a society is just, rejecting Equal Value to Saving Lives is not unjust. ${ }^{10}$

Singer et al.'s argument faces two problems. First, its contractarian premise is questionable: even if the veil of ignorance were an appropriate device for selecting the basic structure of society - a debatable claim - it might not be appropriate for priority-setting decisions within that basic structure. We do not pursue this concern further here. Second, even if the veil of ignorance were a good tool for assessing allocative principles, Singer et al.'s expected utility theory of rationality is open to challenge. Rawls himself denied the rationality of maximizing expected outcome in choosing the basic structure of society behind a veil of ignorance. Instead, he advocated the 'maximin' strategy of optimizing the position of the worst off (Rawls 1971: 152-157). ${ }^{11}$ He argued that under certain conditions, which are present in his hypothetical choice situation, it is rational to sacrifice some expected gains to secure the 'best worst' outcome (1971: 152-154). ${ }^{12}$

It is easier to see that the rational response to the choice situation Singer et al. describe is not obvious if we recognize that the choice behind the veil is really a choice between whole lives. For simplicity, assume that both people whose lives could be saved are 40 years old at time $t$ and would live another 40 years if saved. The rational egoist must choose whose life will be saved at $t$, but will live the whole life of one of the two people. From behind the veil her choice is between: (1) a 50\% chance of

10 We could also determine who will be saved on the basis of a coin toss. If we did so, there would be a $25 \%$ chance that you would live a life with 0.55 health utility after $t$, a $25 \%$ chance that you would live a life with a 1.0 health utility after $t$, and a $50 \%$ chance that you would die at $t$. This is worse for you than if the person with a 1.0 health utility were saved, so this is not what you would rationally choose.

11 Singer et al. discuss Rawls' view, saying that 'there have long been good grounds for thinking that in A Theory of Justice Rawls 'cooked the books' in order to derive from his hypothetical device the principles that he believed squared with our considered moral judgments about justice', a claim which Singer $e t$ al. believe Rawls has effectively conceded (1995: 149). It may be the case that Rawls 'cooked the books', and it may further be the case that his maximin principle is not implied by veil of ignorance reasoning. However, it does not follow from this that no risk-averse weighted social utility function can plausibly be supported by veil of ignorance reasoning.

12 For further discussion, see also Buchak (2013) and Broome (1990). For a discussion of the relationship between risk-aversion and weighted social welfare functions, see Harsanyi (1975) and Broome (1991). 


\begin{tabular}{lccc}
\hline & Option $X$ & Option $\mathrm{Y}$ & Option $\mathrm{Z}$ \\
\hline Alice & 45 years (blind) & - & - \\
Beth & - & 60 years (blind) & 35 years (full health)
\end{tabular}

TABLE 1. Rejecting Equal Value to Saving Lives (Beckstead and Ord 2013: 234).

living 80 years with a quality of life of 0.55 and a $50 \%$ chance of living 40 years with a quality of life of 1.0; or (2) a 50\% chance of living 80 years with a quality of life of 1.0 and a $50 \%$ chance of living 40 years with a quality of life of 0.55. Although lifetime expected well-being is maximized by choosing the second option, it is not obvious that a rational egoist should choose that option. If she ends up with the lower-quality life, she will also end up with a much shorter life, because of an allocation rule that places less value on extending her life than one of higher quality. Thus, for those who do not already accept the use of expected utility theory for allocation decisions, Singer et al.'s argument does not provide further reasons to accept a simple utilitarian social welfare function.

Beckstead and Ord (2013) provide another argument for rejecting Equal Value to Saving Lives. They invite us to imagine two otherwise healthy 20-year-olds, Alice and Beth, who have recently contracted an unusual disease. The disease will kill them very soon if they are not treated, and even if treated they will be left blind or with a reduced lifespan. We do not have enough resources to treat them both. Our treatment options are as shown in Table 1.

After considerable research and reflection, Beth has a strong preference for 35 years of life at full health over 60 years of life blind (for Beth, a year of blindness therefore has a QALY score of $\leq 0.58$ ).

No matter which option we choose, Beckstead and Ord argue, we face a counter-intuitive conclusion. Choosing Option X exhibits a Preference for Smaller Benefits with respect to Option Y. It seems that we should not prefer giving Alice 45 years of blind life rather than giving Beth 60 years of blind life (assuming blindness is equally bad for both). Y results in a Pointless Violation of Autonomy: Beth strongly prefers Option Z to Option Y, but we are giving her $Y$ anyway. $Z$ results in Disability Discrimination: if we prefer option $Z$ to option $X$, then we are choosing to give Beth 35 years sighted rather than give Alice more years living blind. Out of these problematic implications, Beckstead and Ord think that Disability Discrimination is the least bad. If they are right, this gives us reason to reject Equal Value to Saving Lives.

However, Beckstead and Ord's conclusion is too fast. First, there are sometimes good reasons to prefer smaller benefits when allocating 
scarce resources. As we argue in section 4, an allocative principle that assigns greater value to a benefit the worse off the beneficiary will sometimes endorse giving someone a smaller benefit. Other nonmaximizing allocative principles would also have this implication. Thus, Beckstead and Ord cannot generalize from the case they describe to the conclusion that we should always pick disability discrimination over providing smaller benefits when faced with life-saving choices between people with different qualities of life. Second, it is not obvious that giving Beth the option she wants less constitutes a violation of autonomy that the allocator of a scarce resource has a duty to respect. If we understand violation of autonomy in a Kantian sense, this would imply that Beth has a right to the treatment option that she prefers. This would indeed mean that there would be something wrong with denying her this option. But it would beg the question at issue, which is about who should be given what. On the other hand, if all that Beckstead and Ord mean is that Beth's preference for $\mathrm{Z}$ constitutes a prima facie reason to give Beth $\mathrm{Z}$, this may be right, but it will be too weak to ground their conclusion that we should accept disability discrimination.

If there are cases in which it is either not irrational to prefer smaller benefits or not wrong to give someone a treatment they do not prefer, then it does not follow that health policymakers should always accept disability discrimination of the kind Beckstead and Ord discuss when allocating scarce health care resources.

\subsection{No Value to Reducing Morbidity}

A second response to the QALY trap is to deny that curing or averting disability has any value when lifesaving allocation decisions are being made. Three different types of argument can be given for this. The first maintains that disabilities do not lower quality of life. A proponent of this view need not object to allocating lifesaving resources on the basis of quality of life, but could nevertheless deny that disability is relevant to doing so. The second two arguments do not deny that disabilities may lower quality of life but deny that quality of life is relevant when allocating lifesaving resources. The strong version holds that saving lives has lexical priority over improving their quality. The weak version accepts value to reducing morbidity but insists that choices concerning life-saving and lifeimproving interventions are separate allocation decisions.

\subsubsection{Disabilities Do Not Lower Quality of Life. The denial that disability} lowers quality-of-life may seem extraordinarily counter-intuitive. However, disability scholars have made a strong case that the quality of life of people with physical impairments is, on average, much higher than recognized by people without such impairments and not substantially 
lower than theirs. ${ }^{13}$ Studies of people with such disabilities suggest that standard quality of life scores like those we have referenced in this paper do not reflect the subjective or objective quality of life for most people with disabilities. People have an immense capacity to adjust their goals and desires with changing circumstances: they have an adaptability and resilience they may not appreciate before such changes. ${ }^{14}$ Thus far we agree with critics who argue that the quality of life scores standardly assigned to most disabilities are far too low, and that accurate assessments require significant input from people with the disabilities in question.

Some scholars go a step further, arguing that physical disability is a mere-difference akin to race, sex, or sexual orientation. Notably, Elizabeth Barnes (2009) maintains that having or acquiring a disability may be a harm, in making life more challenging, without being a 'negative difference-maker' that makes life go worse overall. Life can be harder with any stigmatized difference, especially in discriminatory environments, but it is not appropriate to 'cure' disability any more than it would be to alter someone's race, sex, or sexual orientation instead of addressing external sources of adversity. ${ }^{15}$

However, the mere-difference claim will not get us out of the QALY trap. First, it is much more plausible for some conditions classified as disabilities than others; for deafness, say, than for Duchenne Muscular Dystrophy (DMD). The former involves the mere lack of a function hearing; the latter, the gradual decline of motor functioning, resulting in disruption, discomfort and early death. Given the multiplicity of ways that people can flourish, a person biologically incapable of hearing who lives in an inclusive environment may do as well as anyone else. Although

13 See, among others, Albrecht and Devlieger (1999) and Brazier (2005). Research also suggests that much of the difference in self-rated quality of life between disabled and non-disabled individuals may be due to social factors (Marinić and Brkljačić 2008).

${ }^{14}$ For some evidence of this, see Ubel et al. (2005: S57). For some evidence to the contrary, see Peeters (2012).

15 This raises the more general point about the role of non-health factors in reducing quality of life for people with disabilities. These factors have a significant impact, but it is not obvious how their effects should be taken into account. It is this interaction of biological and social factors that lead John Broome (2002: 95) to question whether it is possible to separately assess health-related quality of life: 'asthma is less bad if you are well-housed, mental handicap is less bad in supportive communities, deafness is less bad if you have access to the internet'. On the one hand, it seems parochial for health care allocators to focus only on clinical measures and ignore the impact of the physical and social environment. On the other hand, as Broome suggests, it seems perverse, even complicit, to assign a lower quality of life estimate for a given health condition in a society with greater disability discrimination than in a society with less discrimination. And yet, as disability advocates would rightly insist, individuals with the same health conditions in the two societies would probably enjoy lives of very different quality. We return to this issue in the final sections of the paper, where we consider how people with disabilities could be prioritized on the basis of their degree of disadvantage. 
some people with DMD can also flourish, the prospects for doing so seem far more limited, and it is difficult to see how any plausible theory of well-being could judge their lives to be equally good on average as those of people without DMD. It would seem far more reasonable for a Deaf person to refuse a 'cure' for her condition than a person with DMD.

Moreover, as Barnes (2014) notes, acquiring (or losing) a mere difference like a disability can involve serious loss and disruption, even if there is nothing worse about a life with or without the disability. So even if 'cure' is problematic, 'prevention' need not be. Were the mere-difference view correct, we would still face difficult tradeoffs between saving lives and preventing losses in quality of life. Finally, even proponents of the mere-difference view do not make the far more radical claim that there are no conditions or circumstances which generally lower expected quality of life. They would have no reason to deny that the life of someone sentenced to life without parole in a maximum security prison would probably be worse than the life of most other people with the same life expectancy. These last two considerations make clear that even if we accepted a meredifference account of disability, it would not be enough to jettison Value to Reducing Morbidity and thereby allow us to escape the QALY trap.

3.2.2. Lexical Priority to Saving Lives. A very different reason for denying the relevance of disabilities to the allocation of scarce health care resources is offered by John Harris. Harris $(1987,1995)$ argues that we should first spend our resources maximizing the number of lives saved, taking no account of quality of life, and only use resources to raise people's quality of life if some are left over. ${ }^{16} \mathrm{He}$ believes that this view is intuitive. But although the notion that death is different from lesser afflictions - differing in kind rather than degree - has some intuitive appeal, Harris' absolutism about the priority of life saving does not.

Though we may disagree about where the line is, most of us can conceive of some lifesaving intervention that would be so costly that our money would be better spent on life-improving interventions. For example, if we must choose between extending one person's life for just a few days and curing a large number of people from a lifetime of chronic pain, most people would surely favour the latter. Harris (1987: 120) admits that there are some exceptions to the lexical priority of saving lives over curing disease. However, even with these limited exceptions, his proposal that we should spend nothing on improving lives until we can do no more to save them runs into serious problems.

16 In later writing, Harris appears to take a more tentative view: 'But how does life-saving of one now count if the alternative is life-enhancing for a much greater number later? This cannot be finally resolved now' (Quigley and Harris 2008). Our interest is in examining the implications of the view Harris articulated in earlier writing. 
Suppose Harris tried to restrict the permissible trade-offs to comparisons between life-saving interventions and very severe diseases. Any such proposal would face the Aggregation Problem (Temkin 1996; Broome 2004: 54). Suppose that we can either (A) prevent one person from dying or (B) prevent two people from experiencing severe pain for the rest of their lives. We judge that B is better than A. (If you find this judgement implausible just increase the number of people suffering until it becomes plausible. As long as there is some point at which you judge the tradeoff to be reasonable, the argument will go through.) Now suppose we can either (B) prevent two people from experiencing severe pain for the rest of their lives or $(C)$ prevent four people from experiencing slightly less pain for slightly less time than those in (B). C is better than B. We can continue to produce cases, one after another, that successively prevent less and less pain for more and more people. Eventually we arrive at $\mathrm{Z}$, which is the option to prevent a massive number of people from undergoing a small amount of pain for a small amount of time (e.g. a headache). We judge $Z$ to be better than $Y, Y$ better than $X, X$ better than $W$, and so on, all the way back to A. By transitivity of betterness, it follows that $\mathrm{Z}$ is better than A. Thus, a sufficiently large number of headaches can outweigh a life. ${ }^{17}$ This continuum argument presents a problem for Harris, who must find a nonarbitrary point on the continuum at which he can claim that one option is worse than the last, no matter how small the difference in suffering and how great the difference in number of people. ${ }^{18}$

A second problem, specific to a view that accords (nearly) strict lexical priority to life-saving interventions, concerns the definition of a life-saving intervention. Consider a patient in an intensive care unit (ICU). During her stay she may undergo many interventions that each qualify as life-saving, e.g. having her heart restarted by defibrillation, having a feeding tube and a ventilator inserted, and receiving medications, fluids and nutrition to sustain her life. Suppose a patient received 15 meals via feeding tube, 70 hours of artificial ventilation, and eight different medications, each necessary, during her stay in the ICU. How many life-saving interventions did she receive? If, as Harris (1987: 120) claims, 'we should give priority

17 Several responses have been given to this challenge, but whether they succeed is contentious. Among them are accounts by Dorsey (2009), Temkin (2012: 135) and Voorhoeve (2014). Against them, see Norcross (1997, 1998a, 1998b, 1999) and Broome (2004: 55-59).

18 Some philosophers believe that the Aggregation Problem is a premise in a sound argument forbidding any aggregation. Harris, rejecting this view, is among the many philosophers who believe that some limited aggregation is permissible. It is this latter group of philosophers who have the most difficulty dealing with the Aggregation Problem. They must draw a principled line above which certain harms have lexical priority over any number of (even slightly) smaller harms. 
to saving as many lives as we can, not as many life-years', we need a plausible way of individuating life-saving interventions.

Imagine that Ahmed can be saved for 20 years with seven clinically distinct procedures, each of which extends his life for some fraction of that time, whereas Belin can be saved for 20 years with a single procedure, costing the same total amount. If each clinically distinct procedure without which Ahmed will die counts as a life-saving intervention, Harris' model implies that we should give treating Ahmed far higher priority than treating Belin, even though both of them are benefiting the same amount. On the other hand, if the seven procedures are counted as one complex intervention, treating Ahmed should be given the same priority as treating Belin. Harris provides no principled basis for individuation. ${ }^{19}$

3.2.3. Separate Decisions for Lifesaving and Cure. Ubel et al. (2000) propose a more nuanced approach. Since people generally accept Equal Value to Saving Lives, within limits, saving the lives of people with most health conditions should be assigned the same 'societal value' as saving healthy lives. However, they insist that the social decision to treat most health conditions as having no disvalue for lifesaving purposes does not preclude assigning substantial value to their cure, since these are 'separate decision[s]' (Ubel et al. 2000: 897). That is, in general, we should give equal value to saving lives and should give value to reducing morbidity, but should not give any added value to reducing morbidity when it occurs in the context of life-saving.

This proposal also runs into difficulties. Suppose there are three possible treatments that we could give to a patient. Treatment A will save their life and simultaneously raise their quality of life. Treatment B will only save their life (for the same duration as Treatment A), and Treatment $\mathrm{C}$ will only raise their quality of life (by the same degree as Treatment A) conditional on their survival. Treatment $A$ therefore provides the same benefits as Treatment B and Treatment C combined. On Ubel et al.'s proposal, we should be willing to pay the same for Treatment $A$ and for Treatment $B$, since both are lifesaving interventions and we should give no value to the benefits of morbidity reduction that lifesaving interventions provide. Furthermore, according to their proposal, we should be willing to pay some amount for Treatment $C$, since society values raising people's quality of life. It follows that health policymakers, if following Ubel et al.'s proposal, should be willing to pay more for Treatments B and C together than for Treatment A, even though they provide exactly the same benefit to exactly the same patient. This seems irrational.

19 This objection could be avoided were Harris to adopt an alternative view which says to give absolute priority to life-years rather than to lives saved. However, Harris rejects such a view (1987: 118), and the view still violates Value to Reducing Morbidity, one of the intuitive principles that sets up the QALY trap. 
Ubel et al. could respond by arguing that giving a patient both Treatment $B$ and Treatment $C$ in one hospital stay should be regarded as giving them one compound treatment, and that we therefore should not pay more for B plus C than for A. But if Treatment B and C are to be considered one compound treatment, we again need an account of the criteria for individuating interventions. Any such account appears vulnerable to a sorites problem. We can stipulate that if we administer two interventions 10 minutes apart they are still one intervention. But will this remain true if we wait a week, a month, or a year to administer $C$ after B? If Ubel et al.'s view is to be defended, they must find a non-arbitrary way of specifying when $B$ and $C$ are one compound treatment and when they are two serial treatments, and it must be shown that it would not be irrational to pay more in the latter case. It is difficult to believe that this challenge can be met.

\subsection{Reject Transitivity of Betterness}

In section 2, we argued that one could not simultaneously defend Equal Value to Saving Lives and Value to Reducing Morbidity while rejecting Unequal Value for Equal Outcomes. However, Frances Kamm argues that we can make all of these moves if we reject our assumption that the betterness relation is transitive.

While it was once widely accepted that the transitivity of betterness is a fundamental axiom of rational choice, recent work by Larry Temkin (1987, 1996, 2012) has made this less obvious. Nonetheless, transitivity of betterness does a lot of heavy lifting in CEA, so we would need an alternative account of rational prioritization if betterness were intransitive.

To see why intransitivity threatens rational prioritization, consider a case Kamm discusses. We must choose between the following three interventions:

I: Save the life of one person at full health.

II: Save the life of one unhealthy person and bring them to full health.

III: Save the life of one unhealthy person.

According to Kamm (2009: 186), and many people's intuitive judgements, Unequal Value for Equal Outcomes is false (I = II), there is Value to Reducing Morbidity (II > III), and there is Equal Value to Saving Lives (III = I). But this implies that I is as good as II is better than III is as good as I (I = II > III = I). This intransitive betterness relationship implies that alternatives I, II and III cannot be ordered, and so we cannot decide between them on the basis of which is better. 
Kamm proposes that when we confront cases like this we may 'decide on the basis of which path leads to the best outcome so long as doing so does not hold anyone's identity for or against him'. Choosing alternative II rather than alternative III, she argues, leads to a better outcome without discriminating against either patient on the basis of their identity since both patients are unhealthy. For this reason, she asserts, we should not choose III. But we cannot prefer II to I, Kamm thinks, because doing so would discriminate against the patient helped by alternative I. If the patient helped by alternative I had been unhealthy rather than healthy before being saved and brought to full health, I and II would be equally choiceworthy. Thus, if we were to choose II over I, we would discriminate against the patient helped by I merely because she is not unhealthy. So, Kamm (2009: 187) argues, when confronted with a choice between I, II and III, we should not choose alternative III, and should give equal priority to I and II, tossing a fair coin to decide between these two alternatives.

One could reasonably complain that Kamm's decision procedure is under-motivated. Why, we might ask, is it discriminatory to choose II rather than I, while it is not discriminatory to give the patient helped by I a chance at a treatment while giving the patient helped by III no chance at the treatment? We do not ordinarily worry about people being discriminated against on the basis of their being too healthy, or nondisabled, but this seems to be Kamm's chief worry. Kamm offers no response to this objection, but we will not press it further.

Our chief concern is that Kamm's proposed decision-making procedure appears to deal with the intransitivity of betterness only by violating the principle of the Independence of Irrelevant Alternatives, which is also widely regarded as a fundamental axiom of rational choice. According to this principle, if $B$ is not preferable to A out of the choice set $[\mathrm{A}, \mathrm{B}]$, introducing a third option that expands the choice set to [A, B, C], must not make B preferable to A. ${ }^{20}$

To see why violating this axiom is problematic, consider the following case:

Healthy and Unhealthy are in the emergency room. Healthy is a patient who is normally in full health and needs Treatment $X$ in order to survive. Unhealthy is a patient who is normally in chronically poor health and also needs Treatment $X$ in order to survive. Emergency room triage staff believe that they should treat Healthy and Unhealthy equally, and should therefore give equal priority to saving each of their lives. Unfortunately, they can only

${ }^{20}$ This is a simplified version of Kenneth Arrow's (1963: 27) original formulation of the principle. The original principle states: 'Let $R_{1}, \ldots, R_{n}$ and $R_{1}^{\prime} 1, \ldots, R_{n}^{\prime}$ be two sets of individual orderings and let $C(S)$ and $C^{\prime}(S)$ be the corresponding social choice functions. If, for all individuals $i$ and all $x$ and $y$ in a given environment $S, x R_{i} y$ if and only if $x R^{\prime} i y$, then $C(S)$ and $C^{\prime}(S)$ are the same'. 
treat one patient, so they decide to toss a fair coin. Just as they are about to do so, Needy is brought into the emergency room. Needy is just like Unhealthy, except that the doctors could save Needy's life and bring him to full health afterwards if they give him treatment $X$. Realizing this, they send Unhealthy away and toss a coin to decide between saving Healthy and Needy. The coin chooses Healthy.

It seems clear that this behaviour is unreasonable, but according to Kamm's decision theory the physicians have acted rightly. According to Equal Value to Saving Lives, Healthy and Unhealthy are to be treated equally in a pairwise comparison. But if we are choosing between treating Healthy and Unhealthy when Needy enters the room, then we must prefer treating Healthy to treating Unhealthy. No decision theory should have these implications for practice. ${ }^{21}$ Given this problem and the unclear motivation for Kamm's decision procedure, we should not go this route. Denying the transitivity of betterness is not the right response to the QALY trap. $^{22}$

\subsection{Accept Unequal Value for Equal Outcomes}

Accepting Unequal Value for Equal Outcomes means giving greater value to saving someone's life and simultaneously bringing them to full health than to saving the life of someone who is already at full health, even though the outcomes of both treatments are the same. Clearly, this is a position in need of a rationale.

One possible rationale is the Causative Principle discussed by Kamm. According to that principle, what matters is not how much good follows an intervention, but how much good the intervention causes. According to Kamm, an intervention that cures disability and confers $x$ years of perfect health causes more good than an intervention that merely confers $x$ years of perfect health. Although the outcome for the individual and society are the same, the intervention causes two gains for the disabled individual in health and in life - but only one for the non-disabled individual - in life.

However, we think that this application of the causative principle is mistaken: in fact, the two interventions cause the same amount of benefit. If we save the life of the able-bodied person, the disabled person dies. If we save the life of the disabled person and make her able-bodied, the able-bodied person dies. In both cases, one patient gets healthy life and the other patient gets death. In neither case does the disabled person continue

${ }^{21}$ Elsewhere, Kamm (2013: 470) recognizes that her opponents argue that her view violates the Independence of Irrelevant Alternatives, but claims that 'such cases help show that the principle is either incorrect or its correct interpretation does not conflict with such a result'.

22 In addition, Gustafsson (2010) has argued that any agent with acyclic, intransitive preferences (like those endorsed by Kamm's view) can be money-pumped. 
to live with her chronic condition. Thus, it is inappropriate to ascertain the benefit the intervention causes by comparing it with a counterfactual state of affairs in which someone lives with a disability. Rather, both interventions cause the survival of one person in a healthy state. It might be a greater achievement for health professionals if they both save a life and restore functioning, but it is hard to see why that should be relevant to allocation decisions.

Although Unequal Value for Equal Outcomes is prima facie implausible and cannot be grounded in the causative principle, we do think that it is sometimes correct. In the next section, we describe an approach to priority-setting that explains why.

\section{A MODERATE PRIORITARIAN SOLUTION TO THE QALY TRAP}

Rather than simply denying Value to Reducing Morbidity, Equal Value to Saving Lives, or the transitivity of betterness, or accepting Unequal Value for Equal Outcomes, it is possible to hold a mixed view. According to the mixed view we prefer, it is sometimes true that equal value should be assigned to saving lives and it is sometimes true that we should give unequal value to outcomes that include the same amount of well-being. Such a view, we believe, can avoid invidious disability discrimination without the problematic implications canvassed in section 3. However, it must also have a principled foundation: the way it avoids the counterintuitive implications of the responses we have criticized should not be ad hoc. We ground our mixed view in prioritarianism. ${ }^{23}$

Prioritarians hold that a benefit is more valuable the worse off the recipient of the benefit. For one person to be worse off than another he must have lower lifetime well-being. ${ }^{24}$ This might be because he is poorer, he faces systematic discrimination, he is a widower, he has lower life-expectancy, or he has a chronic disease or disability. In a prioritarian scheme, patients with these kinds of welfare disadvantages would be given some priority for treatment over patients without such disadvantages. (Among philosophers and health policy experts, it is highly controversial whether non-health considerations should play a role in determining which patients are prioritized for which intervention. We believe that all welfare considerations should, in principle, be taken into account by health policymakers, but our prioritarian solution to the QALY trap is compatible with the view that health care professionals should only

23 As we note at the end of this section, there are alternative principled foundations for the mixed view we endorse. Thus one does not have to be a prioritarian at a foundational level in order to adopt our solution to the QALY trap.

${ }^{24}$ For an exposition of this view, see Sharp and Millum (2015). 


\begin{tabular}{lcccccc}
\hline & \multicolumn{2}{c}{ Treat Cecile } & & \multicolumn{2}{c}{ Treat Roberto } \\
\cline { 2 - 3 } \cline { 6 - 7 } & Cecile & Roberto & & Cecile & Roberto \\
\hline Pre-intervention QALYs & 40 & 20 & & 40 & 20 \\
Post-intervention QALYs & 40 & 0 & & 0 & 20 \\
\hline
\end{tabular}

TABLE 2. Lifetime QALY distributions.

consider health-related quality of life in determining who to prioritize for an intervention. ${ }^{25}$ )

The amount of priority given to worse-off patients depends on which version of prioritarianism is adopted. An extreme version, leximin, states that benefits should always be distributed to the worst-off person. ${ }^{26}$ Such a view is implausible: it implies that trivial benefits to the worst off person outweigh massive benefits to others who are also in great need. We favour a moderate prioritarianism, which allocates benefits on the basis of a combined measure of the amount of benefit provided and the degree of disadvantage of the beneficiaries, so that a benefit is given greater weight the more disadvantaged the beneficiary would otherwise be. The application of moderate prioritarianism to health care priority setting is widely endorsed by philosophers and bioethicists. ${ }^{27}$ Its relevance to the QALY trap and the issue of disability discrimination, however, has been comparatively neglected.

If we allocate health resources on the basis of a moderate prioritarianism, we can simultaneously affirm Value to Reducing Morbidity and the transitivity of betterness, give theoretical motivation for accepting the most intuitively plausible cases of Unequal Value for Equal Outcomes, and preserve what is most important about Equal Value to Saving Lives, all in a principled way.

To illustrate how moderate prioritarianism preserves the moral core of Equal Value to Saving Lives, consider a case in which we must decide between two patients for a life-saving intervention (Table 2). Both have lived 40 years and will die without treatment. Both, if treated, will live 40 more years. Cecile will be at full health throughout her life, while Roberto has a congenital disease that lowers his health-related quality of life to 0.5. For ease of presentation we use QALYs as the unit of advantage.

${ }^{25}$ For arguments against a 'separate spheres' approach to setting priorities for health spending that we find compelling, see Broome (2002) and Sharp and Millum (2015: 8-10).

26 This view faces criticism from Fleurbaey et al. (2009).

27 See, among others, Ubel et al. (2000: 893-894), Brock (2006: 212-215), Kamm (2009: 156157) and Nord et al. (2009: S12). 
Treating Cecile produces an 80:20 distribution: Cecile gets 80 QALYs across her life and Roberto gets 20 QALYs across his life. If we allocate resources in a straightforwardly aggregationist way, we will treat Cecile, since doing so will produce 40 QALYs, while treating Roberto will only produce 20 QALYs. Treating Roberto produces a 40:40 distribution: each patient gets a total of 40 QALYs in their life. A moderate prioritarian is likely to judge that the second distribution is better than the first. Although it contains less total benefit (80 instead of 100), it gives greater priority to the worse-off patient. On a moderate prioritarianism that gives sufficient priority to benefiting the worst-off, we should treat Roberto even though he has a chronic disease that makes his quality of life lower than Cecile's. Thus, prioritarianism does not tell us to systematically prefer saving the lives of healthy and able-bodied people over the lives of unhealthy or disabled people.

Note, again, that moderate prioritarianism does not give absolute priority to the worst-off. When the benefits of treating the worse off person are sufficiently low, our scheme will sometimes tell us to save the better off person. Suppose that in the case above Roberto's life could only have been extended by four years rather than 40 years. If that were the case, treating Roberto would only produce 2 QALYs. We would therefore have to choose between providing Cecile with an additional 40 QALYs and providing Roberto with an additional 2 QALYs. Because moderate prioritarianism tells policymakers to care both about a patient's degree of disadvantage and the amount of benefit they can provide her, a plausible moderate prioritarianism would recommend saving Cecile rather than Roberto in this second case.

Our proposed scheme therefore does not give categorical preference to saving patients with high quality of life or patients with low quality of life. Just how frequently we should prefer to save those whose usual quality of life is low depends upon how much priority is given to treating the worst-off. Moderate prioritarianism does not entail Equal Value to Saving Lives. But the view does tell us not to systematically prefer saving the lives of non-disabled people over the lives of disabled people. The systematic preference for saving non-disabled people seems to be at the heart of the disability discrimination objection to standard aggregation.

In some cases, our scheme would endorse Unequal Value for Equal Outcomes. Consider the case in which we could save the life of a healthy person or both save the life and cure the disease of an unhealthy person. If the latter had endured this condition for some time and so had experienced a significantly lower quality of life, she would be worse off. We should therefore give greater priority to treating her, even though it would provide the same benefit as treating the healthy patient. But in situations where the patient became chronically ill only very recently, it seems less plausible to regard her as significantly worse off. 
Our moderate prioritarianism would then tell us to treat the patients equally.

Finally, it is easy to see why a moderate prioritarianism vindicates Value to Reducing Morbidity and the transitivity of betterness (as a plausible view ideally should). Because moderate prioritarianism takes all benefits into account, it will always respond positively to a pure increase in benefits - as in the case of morbidity reduction. And because moderate prioritarianism can be represented by a weighted utility function, its betterness relation is always transitive.

In addition to these reasons in favour of a moderately prioritarian solution to the QALY trap, the view is ecumenical. The great majority of philosophers and health economists believe that we should give higher priority to the worst-off, although they may disagree about the details and underlying justification. ${ }^{28}$ In addition to prioritarians, for example, there are some philosophers who accept lifetime egalitarianism, a form of value pluralism implying that both welfare and equality are constituent parts of the good (Temkin 1993). In practice, lifetime egalitarianism and lifetime prioritarianism will be virtually co-extensive for the cases regarding the allocation of scarce resources with which we are concerned. ${ }^{29}$ Lifetime egalitarians can therefore adopt our solution to the QALY trap. Even those who favour a utilitarian distribution of resources can accept our model, for the same reason that they can accept, for example, affirmative action policies. Giving priority to the worst-off and reducing inequality in society will almost certainly have a substantially positive effect on the far-future, which should be of much greater concern to utilitarian philosophers than the mere optimization of distributions in the present and near-future (Beckstead 2013). ${ }^{30}$ Finally, those who come at resource distribution from a

${ }^{28}$ In the words of Wolff and de-Shalit (2007: 3-4): '[P]rovided that there are people in a society who have not yet achieved sufficiency, and provided that we have in mind limited, or at least finite, budgets and financial resources, then all of these views appear to converge on the same general policy prescription in the short to medium term: identify the worst off and take appropriate steps so that their position can be improved' (authors' italics).

${ }^{29}$ Cf. Voorhoeve and Fleurbaey (2016), which discusses the ways which prioritarianism and egalitarianism come apart in population ethics. Voorhoeve and Fleurbaey do not disagree that prioritarianism and egalitarianism are virtually co-extensive in the cases we discuss. Since both views have the same implications, their ability to provide this solution to the QALY trap does not provide evidence for preferring one view over the other.

${ }^{30}$ It should be noted that Singer et al. (1995: 149-150) make this concession with respect to the QALY trap. While it is not in principle unjust to give greater value to saving lives that contain more well-being, they claim, what we really ought to care about is maximizing utility, and 'there is more to overall utility than health-related QALYs'. They write: 'It is plausible to suppose that tilting the balance of health care towards the more disadvantaged members of society will reinforce feelings of concern and sympathy, and lead to a more compassionate society. This in turn may be a society with more community feeling and therefore one that provides a higher level of general welfare than a less 
liberal egalitarian angle also have reason to accept our conclusion. In practice, no policy will be sufficiently fine-grained to distinguish a prioritarian model of resource distribution from a liberal egalitarian model that provides extra resources to those who are disadvantaged for the sake of fair equality of opportunity. Thus, models of fair resource allocation should converge in their insistence on both efficiency and reducing disadvantage.

Applying a moderate prioritarian view both has plausible implications for individual cases and is theoretically grounded by foundational principles that are supposed to underlie allocation schemes outside as well as inside the domain of priority setting for health spending. These are powerful reasons in favour of accepting its resolution of the QALY trap.

\section{OBJECTIONS}

\subsection{The Proposal Fails to Eliminate Disability Discrimination}

Under our proposal, people with those disabilities that reduce their quality of life will have their priority for life-saving health care resources lowered in virtue of the lower benefits that saving their lives provides, but raised in virtue of their being made worse off by the reduction in their quality of life. The lives of people with disabilities would therefore not, in general, be treated as having lesser value. The value will depend on the extent to which their disabilities make them worse off and on the additional weight their survival receives by virtue of their being worse off. For the same reason, our proposal generally avoids 'double jeopardy': the priority assigned to worse-off individuals would mitigate rather than compound any disadvantage arising directly from their disabilities.

Nonetheless, some might object that prioritarian 'compensation' would only add discriminatory insult to injury by treating people with those disabilities not as equals but as especially needy. This objection can be met by two further considerations. First, as we argued in section 3.2.1, quality-of-life adjustments should be based in large part on judgements made by people who have lived with the conditions being assessed. If a condition, such as deafness, is assessed through an inclusive process as having only a negligible impact on quality of life, it would also receive lower priority for prevention and 'cure' - a consequence reflecting the judgements of those living with the condition. If, on the other hand, people living with a particular disability regarded their lives, on average, as much worse because of it, saving their lives would provide them with lower expected benefit. But they would also receive higher priority for life-saving resources because their disability made them worse off. Thus,

compassionate society.' Moreover, it may be 'important to act in ways that go beyond abstract justice or fairness, instead tilting the balance so that it favours those who would otherwise feel themselves arbitrarily disadvantaged'. See also Singer (1993: 16-54). 
our proposal would avoid or mitigate any insult in compensating people with disabilities for their disadvantages, because it would generally compensate them only for conditions that they themselves (or their representatives) judged as disadvantageous.

Second, our approach is consistent with treating disabilities no differently than other health and non-health conditions that reduce overall quality of life. This includes not only permanent impairment and chronic disease but also poverty, poor education, and other sources of social inequality. Again, the reduction in expected quality of life in saving people who experience any of these conditions could be offset by the priority they receive for having lived with them. Our approach, in theory, treats disabilities as just one possible source of lower quality of life; it need not single them out for special treatment.

\subsection{Double Jeopardy for the Victims of Recent Misfortune}

Our approach has harsher consequences for previously well-off individuals only recently placed in a state that lowers their quality of life. A person who has just contracted rheumatoid arthritis (or, on a broader approach, become divorced, or lost a child) would have lower priority for lifesaving treatment by virtue of the reduction in her expected quality of life going forward. But that reduction would not be offset by her status as worse off, at least in the short term, since her quality of life has only recently become low. Some might regard this as troublesome. ${ }^{31}$

We accept that the proposed scheme will sometimes, at least in principle, have harsh implications for people who have been well-off until now, but whose lives, if saved, would be lived at lower levels of wellbeing. But this is an implication of any prioritarian approach that takes the unit of concern as the individual over her whole life rather than in her present condition. It is, in effect, no different than preferring to save the life of a person who can be fully cured of her injuries over the life of someone whose injuries will cause him to continue suffering terribly if he is saved. Another, more benign implication, is that the newly better-off will not be penalized for their recent improvement. Someone who has just been cured of a long, painful, debilitating illness would still enjoy priority for lifesaving resources, because their life has still been bad overall. For the kind of moderate prioritarianism we endorse, what offsets expected benefit is not the individual's present condition, but their life as a whole.

\subsection{Implementation Challenges}

Finally, there are several challenges that might be raised regarding the implementation of lifetime prioritarianism in helping to set priorities for

31 Singer et al. (1995: 147) also push this point. 
health care spending. First, in addition to quantifying how much health care interventions benefit their recipients, a prioritarian must also provide weights that quantify how much priority people with different degrees of disadvantage should receive. ${ }^{32}$ Though, as we mentioned above, there is widespread agreement that those who are worse off should receive some additional priority for health care, there is not the same level of agreement about how much priority they should receive.

This is, of course, a general problem for anyone trying to incorporate concerns about the distribution of benefits into decision-making. Anyone who thinks that an allocation scheme should care about more than just maximizing total benefit must have some way of accounting for the other considerations that matter. This is a challenge that we acknowledge, but cannot attempt to address in this paper. It is worth noting that the practical challenge does not appear to be insurmountable. Various tools already exist for incorporating equity or priority concerns into CEA (Johri and Norheim 2012: 125). The Norwegian National Committee on Priority Setting in Health Care recently proposed a new system for deciding which new treatments would be funded through the public health system that explicitly attempted to capture the degree of disadvantage of the beneficiaries of health care, in addition to the amount that they would be expected to benefit (Ottersen et al. 2016). But even if disagreement about the relative weights remains, it does not follow that we would be better off adhering to standard CEA, which is the equivalent of giving no priority to those who are worse off.

Second, lifetime prioritarianism resolves the QALY trap because of its backwards-looking character: it is only if those who are expected to have lower quality of life if their lives are saved have also had a lower quality of life in the past that they get extra priority for life-saving interventions. This might be considered problematic in two respects. ${ }^{33}$ One is that it may seem counterintuitive that someone who was ill in the distant past should thereby gain a claim to higher priority for treatment for an unrelated condition in the present. Why should you get treated now just because you were 'lucky' enough to be ill as a child? In response, note first that it is common to think that someone's past losses can ground a reason to provide them with compensating benefits in the future - there is nothing peculiar about a normative view that incorporates backwards looking elements. ${ }^{34}$ Further, the case may seem more intuitive if we fill in details such that the person getting priority for a benefit now was

32 We thank an anonymous reviewer for the journal for prompting us to consider this concern.

${ }^{33}$ We thank an anonymous reviewer for the journal for suggesting both of these concerns.

${ }^{34}$ More complete arguments in favour of taking into account the lifetime distribution of advantage when making allocation decisions are rehearsed elsewhere. For arguments in 
sufficiently badly off in the past to warrant it. Suppose she spent years of her childhood wracked with a debilitating and painful illness that kept her in and out of hospitals and prevented her from forming close relationships with her peer group. In such a case we do not find it counterintuitive to think that she now deserves higher priority for scarce resources.

The other way in which the backwards-looking character of lifetime prioritarianism might be considered problematic concerns its epistemic demands. Putting lifetime prioritarianism into practice would appear to require investigating people's prior quality of life. Such investigation might seem impractical, as well as intrusive. In response, note that this problem arises in terms of forward-looking considerations, too. As long as the quality of life that patients experience with and without a health intervention is considered relevant to whether that intervention should be funded, we have to investigate what that quality of life is. Answering the relevant empirical questions may be challenging, but it is essential to any cost-effectiveness assessment. Whatever those challenges are, there is no reason to think that they are greater when it comes to patients' history, rather than their prognoses. In fact, in one respect, answering the historical question is easier: the past has already happened. We therefore do not suffer from as much uncertainty regarding people's histories as we do regarding what the effects of allocation decisions will be going forward.

\section{CONCLUSION}

We have attempted to illuminate the discussion surrounding CEA and disability discrimination by critically assessing the main ways philosophers have responded to the QALY trap. We have argued that their proposals all have serious problems. The prioritarian approach we propose recognizes that a health care allocation scheme cannot ignore the expected benefit of the resources it assigns, although that means favouring some lives over others on the basis of expected outcome. At the same time, it insists that expected benefit cannot be the only consideration. The past matters as well as the future, and people who have endured poor health or low quality of life have stronger claims to scarce resources on that basis. Applying moderate prioritarianism in the way we have proposed provides a principled way to allocate scarce health care resources without discriminating against people with disabilities.

favour of lifetime prioritarianism, see Sharp and Millum (2015). For arguments in favour of lifetime egalitarianism, see Temkin (1993: 233-240). 


\section{ACKNOWLEDGEMENTS}

This article was presented at the American Society of Bioethics and Humanities, Priority Setting in Global Health - 2020, and the National Institutes of Health Clinical Center, Department of Bioethics. We thank those present for their contributions. We are also grateful to David DeGrazia, Douglas MacKay, the editors of this journal, and two anonymous referees for their comments. Disclaimer: The views expressed are the authors' own. They do not represent the position or policy of the National Institutes of Health, U.S. Public Health Service, or the Department of Health and Human Services. Funding Support: This work was supported, in part, by intramural funds from the National Institutes of Health Clinical Center.

\section{REFERENCES}

Albrecht, G. L. and P. J. Devlieger. 1999. The disability paradox: high quality of life against all odds. Social Science and Medicine 48: 977-988.

Arrow, K. J. 1963. Social Choice and Individual Values (2nd edn). New Haven, CT: Yale University Press.

Barnes, E. 2009. Disability, minority, and difference. Journal of Applied Philosophy 26: 337-355.

Barnes, E. 2014. Valuing disability, causing disability. Ethics 125: 88-113.

Beckstead, N. 2013. On the Overwhelming Importance of Shaping the Far Future (Dissertation).

Beckstead, N. and T. Ord. 2013. Rationing and rationality: the cost of avoiding discrimination. In Inequalities in Health: Concepts, Measures, and Ethics, ed. N. Eyal, S. Hurst, O. Norheim and D. Wikler, 232-239. Oxford: Oxford University Press.

Bognar, G. 2010. Does cost effectiveness analysis unfairly discriminate against people with disabilities? Journal of Applied Philosophy 27: 394-408.

Brazier, J. 2005. Evaluating the 'disability paradox' in conjunction with resource allocation. Virtual Mentor 7.

Brock, D. 2006. Ethical issues in the use of cost effectiveness analysis for the prioritization of health care resources. In Public Health, Ethics, and Equity, ed. S. Anand, F. Peter \& A. Sen, 201-224. Oxford: Oxford University Press.

Brock, D. 2009. Cost-effectiveness and disability discrimination. Economics and Philosophy 25: 27-47.

Broome, J. 1990. Rationality and the sure-thing principle. In Thoughtful Economic Man, ed. G. Meeks, 74-102. Cambridge: Cambridge University Press.

Broome, J. 1991. Weighing Goods: Equality, Uncertainty and Time. Oxford: Blackwell.

Broome, J. 2002. Measuring the burden of disease by aggregating well-being. In Summary Measures of Population Health: Concepts, Ethics, Measurement and Applications, ed. C. J. Murray, J. A. Salomon, C. Mathers and A. D. Lopez, 91-113. Geneva: World Health Organization.

Broome, J. 2004. Weighing Lives. Oxford: Oxford University Press.

Buchak, L. 2013. Risk and Rationality. Oxford: Oxford University Press.

Dorsey, D. 2009. Headaches, lives and value. Utilitas 21: 37-58.

Fleurbaey, M., B. Tungoddena and P. Vallentyne. 2009. On the possibility of nonaggregative priority for the worst off. Social Philosophy and Policy 26: 258-285.

Gustafsson, J. E. 2010. A money-pump for acyclic intransitive preferences. Dialectica 64: 251257.

Harris, J. 1987. QALYfying the value of life. Journal of Medical Ethics 13: 117-123. 
Harris, J. 1995. Double jeopardy and the veil of ignorance: a reply. Journal of Medical Ethics 21: 151-157.

Harsanyi, J. 1975. Nonlinear social welfare functions. Theory and Decision 6: 311-332.

Johri, M. and O. F. Norheim. 2012. Can cost-effectiveness analysis integrate concerns for equity? Systematic review. International Journal of Technology Assessment in Health Care 28: $125-132$.

Kamm, F. 2009. Aggregation, allocation of scarce resources, and the disabled. Social Philosophy and Policy 26: 148-197.

Kamm, F. 2013. Bioethical Prescriptions. Oxford: Oxford University Press.

Lin, M.R., H. F. Hwang, K. P. Chung, C. Huang and C. Y. Chen. 2006. Rating scale, standard gamble, and time trade-off for people with traumatic spinal cord injuries. Physical Therapy 86: 337-344.

Marinić, M. and T. Brkljačić. 2008. Love over gold - the correlation of happiness level with some life satisfaction factors between persons with and without physical disability. Journal of Developmental and Physical Disabilities 20: 527-540.

National Institute of Health and Clinical Excellence. 2005. Social Value Judgements: Principles for the Development of NICE Guidance. London: NICE.

Norcross, A. 1997. Trading lives for convenience: it's not just for consequentialists. Southwest Philosophical Review 13: 29-37.

Norcross, A. 1998a. Great harms from small benefits grow: how death can be outweighed by headaches. Analysis 58: 152-158.

Norcross, A. 1998b. Speed limits, human lives, and convenience: a reply to ridge. Philosophy and Public Affairs 27: 59-64.

Norcross, A. 1999. Comparing harms: headaches and human lives. Philosophy and Public Affairs 26: 135-167.

Nord, E., N. Daniels and M. Kamlet. 2009. QALYs: some challenges. Value in Health 12: S10S15.

Ottersen, T., R. Førde, M. Kakad, A. Kjellevold, H. O. Melberg, A. Moen, A. Ringard and O. F. Norheim. 2016. A new proposal for priority setting in Norway: open and fair. Health Policy 120: 246-251.

Peeters, Y., D. M. Smith, G. Loewenstein and P. A. Ubel. 2012. After adversity strikes: predictions, recollections and reality among people experiencing the onset of adverse circumstances. Journal of Happiness Studies 13: 589-600.

Quigley, M. and J. Harris. 2008. Personal or public health. In International Public Health and Ethics, ed. M. Boylan, 15-30. New York, NY: Springer Science + Business Media B.V.

Rawls, J. 1971. A Theory of Justice. Cambridge, MA: Harvard University Press.

Sharp, D. and J. Millum. 2015. Prioritarianism for global health investments: identifying the worst off. Journal of Applied Philosophy. doi: 10.1111/japp.12142.

Singer, P. 1993. Practical Ethics (2nd edn). Cambridge: Cambridge University Press.

Singer, P., J. McKie, H. Kuhse and J. Richardson. 1995. Double jeopardy and the use of QALYs in health care allocation. Journal of Medical Ethics 21: 144-150.

Temkin, L. 1987. Intransitivity and the mere addition paradox. Philosophy and Public Affairs 16: $138-187$.

Temkin, L. 1993. Inequality. Oxford: Oxford University Press.

Temkin, L. 1996. A continuum argument for intransitivity. Philosophy and Public Affairs 25: 175-210.

Temkin, L. 2012. Rethinking the Good. Oxford: Oxford University Press.

Ubel, P. A., J. Richardson and J. P. Prades. 1999. Life-saving treatments and disabilities: are all QALYs created equal? International Journal of Technology Assessment in Health Care 15: 738-748.

Ubel, P. A., E. Nord, M. Gold, P. Menzel, J. L. Prades and J. Richardson. 2000. Improving value measurement in cost-effectiveness analysis. Medical Care 38: 892-901. 
Ubel, P. A., G. Loewenstein, N. Schwarz and D. Smith. 2005. Misimagining the unimaginable: the disability paradox and health care decision making. Health Psychology 24: S57-62.

Voorhoeve, A. 2014. How should we aggregate competing claims? Ethics 125: 64-87.

Voorhoeve, A. and M. Fleurbaey. 2016. Priority or equality for possible people? Ethics 126: 929-954.

Wolff, J. and A. de-Shalit. 2007. Disadvantage. Oxford: Oxford University Press.

\section{BIOGRAPHICAL INFORMATION}

Tyler M. John is a fellow at the National Institutes of Health Clinical Center, Department of Bioethics. His current research focuses on the moral desiderata for scarce resource allocation schemes and on human obligations to sentient non-human animals. He began a PhD in Philosophy at Rutgers UniversityNew Brunswick in autumn 2016.

Joseph Millum is head of the Unit on International Health Policy in the Clinical Center Department of Bioethics and staff bioethicist for the Fogarty International Center, National Institutes of Health. His current research focuses on the rights and responsibilities of parents, informed consent, international research ethics, and priority-setting for global health. He is coeditor of the book Global Justice and Bioethics (Oxford University Press, 2012).

David Wasserman is on the faculty of the Department of Bioethics, National Institutes of Health. He is the author, with David Benatar, of Debating Procreation: Is It Wrong to Reproduce? (Oxford University Press, 2016) and, with Anita Silvers and Mary Mahowald, of Disability, Difference Discrimination: Perspectives in Justice and Bioethics (Rowman and Littlefield, 1998). He is the editor, with Adam Cureton, of the forthcoming Oxford Handbook of Philosophy and Disability, and, with Jerome Bickenbach and Robert Wachroit, of Quality of Life and Human Difference: Genetic Testing, Health Care, and Disability (Cambridge University Press, 2005). 